\title{
EAl Endorsed Transactions

\section{OSCase: Data Schemes, Architecture and Implementation details of Virtual Patient repurposing in Multi User Virtual Environments.}

\author{
P. E. ANTONIOU ${ }^{1,}$, L. IOANNIDIS ${ }^{1}$ and P. D. BAMIDIS ${ }^{1, *}$
}

${ }^{1}$ Medical Physics Laboratory, Medical School, Aristotle University of Thessaloniki, Thessaloniki, Greece

\section{Abstract}

Experiential game based learning has proven effective at engaging and enabling learners especially in medical education where the volume of the curriculum is as severe as its criticality. A mature and promising ICT tool for medical education is the Virtual Patient (VP). Web-based virtual patients have been established for quite some time, while efforts have been made to create content in multi user virtual environments (MUVEs). What is still missing is a streamlined method for transferring VPs from Web-based authoring and deployment platforms to MUVEs like OpenSim. This work describes the existing implementation context for repurposing VPs in the OS MUVE. Then it focuses on a novel OpenSim Case Datascheme and a supporting framework that facilitates this streamlined transfer according to previous repurposing strategies and efforts. Finally the future directions and the place of this work in the wider context of contemporary Virtual Learning Environments are explored.

Keywords: Virtual Patients, Mutliuser Virtual Environments, OpenSim, OpenLabyrinth, medical education, Content repurposing, Immersive Environments and Multidimensional Spaces, Virtual and mixed-reality for education, Collaboration and Social Computing in Education, Multi-modal Learning Environments, Non-leisure Games and Gamification

Received on 3 November 2015, accepted on 19 February 2016, published on 27 June 2016

Copyright (c) 2016 P.E. Antoniou et al., licensed to EAI. This is an open access article distributed under the terms of the Creative Commons Attribution licence (http://creativecommons.org/licenses/by/3.0/), which permits unlimited use, distribution and reproduction in any medium so long as the original work is properly cited.

doi: 10.4108/eai.27-6-2016.151523

\section{Introduction}

Medical educational content explosion [1] combined with the crucial character of the healthcare subject matter, has led educational endeavors to turn towards novel and more diverse resources, means and activities including the digital [2]. The overall aim of these endeavors is the open and ubiquitous access to tools and resources that can aid in clinical skill development [3]. In that front, Information, Communication Technologies and especially the Web, become key medical education enablers, able to provide the tools for immediate, interactive learning environments independent from time and space restrictions [4].

An established and effective ICT tool for enabling medical education is the Virtual Patientt has been formally defined by the MedBiquitous Consortium as "interactive computer simulations of real-life clinical scenarios for the purpose of medical training, education, or assessment" [5]. Immediate outcomes in efficacy has led to efforts starting and formalized, for several years now, to an International Standard facilitating exchangeability and transfer of VPs [6], [7], [8]. This overall VP acceptance with subsequent development of platforms that can enable web based streamlined content authoring and publishing, has facilitated a diverse pool of learning modalities, episodes and resources such as project/problem-based learning lectures and exams, as well as both asynchronous and synchronous e-learning sessions [9]. This widespread adoption of VPs had subsequently led to efforts for specialization and contextualization to their design models

*Panagiotis D. Bamidis, bamidis@med.auth.gr 
at, even, the level of particular specialties of medical practice. [10].

This path of proliferation that the Virtual Patient has followed, led to the development of several VP publishing and authoring tools and platforms. A widely accepted such platform is OpenLabyrinth (OLab) [11]. OLab is defined in its user guide as "...an open source online activity modelling system that allows users to build interactive 'game-informed' educational activities such as virtual patients, simulations, games, mazes and algorithms. It has been designed to be adaptable and simple to use while retaining a wealth of game-like features." [12]. It is web based, accessible from all major browsers, with minimal hardware requirements and appropriate learning curve. These features make it suitable for offering and testing novel learner centric approaches in medical education.

OpenLabyrinth, is used in many academic institutions due to its open source nature. It consists of a toolset that allows authoring and publishing of a multitude of pathway based educational activities [11]. It has a graphically driven (code-less), user friendly interface [13] thus reducing the level of IT knowledge required for its use. It is also compliant to the aforementioned MedBiquitous standard and in that capacity it has become a very popular VP tool for authoring and publishing in medical education [14].

In its iterative development and extension, through its widespread use OpenLabyrinth addressed a key initial weakness, that is, a limited capacity for describing virtual patient resources for purposes of search retrieval and discoverability. Specifically it did not offer a specific, clear and, importantly, a standards-based solution for transparent sharing of virtual patients. Through endeavors such as the mEducator project [15] OpenLabyrinth was extended through specific modules addressing these needs. OLabX, as the module was nominated, aimed to address them by applying a specific metadata schema in order to allow VPs to be shareable, described, and semantically annotated for search. OLabX provides a standards infrastructure for VP repurposing and sharing allowing for transferability of this contemporary medical educational digital medium and content. These provisions enhance content crosspollination and silo breaking amongst medical institutions and individuals [15]. In that direction, efforts for evaluation and validation of VPs as individual autonomous learning tools as well as assistive educational resources are beginning to emerge incorporating this medium and measuring both reusability, usability and efficacy both for content authors but especially for students [15][16].

On a another, different, but highly relevant to educational engagement front, three-dimensional multiplayer oriented virtual environments have been utilized as presentation front-ends of VPs. Multi User Virtual Environments (MUVEs) have been used for deploying virtual patients for increasing impact, presence and immediacy of a learning endeavor in especially in a highly "game-aware" demographic of higher education learners [17], [18]. MUVEs or "Virtual Worlds" have been defined as "A synchronous, persistent network of people, represented as avatars, facilitated by networked computers" [19].
This definition includes itself the educational edges that this platform provides. Networking, persistent and synchronous is a major collaboration facilitator while, the sense of presence that a customizable human representation of the user offers, creates an immersive and immediate sense of presence [18]. These factors all are inherently assistive towards the overall educational endeavor goal.

Again, regarding specifics, while major criticisms have been put forward for them [20], [21], one of the most widely used MUVEs for medical content deployment has been Second Life (SL) and its open source counterpart OpenSim (OS). These platforms have been used as treatments aids in instances where patient immersion is intuitive relevant. These would include weight maintenance studies [22], addiction studies [23], and sexual health awareness [24]. Health care resources in these platforms also deal with mental health including delusional beliefs [25], the psychodynamics of transference [26] and social anxiety disorder [27], [28].

On straightforward medical education topics, these platforms have a diverse and significant portfolio. From the general, like anatomy [29], to the specific pneumology [30], pediatric primary care [31], to the manually highly specialized such as emergency medicine and care [32], [33] and cardiopulmonary resuscitation [34], [35], all the way to socially relevant topics like disability health care [36], all these topics exist. Even in pharmacy student training these MUVEs have been used both for general training [37] and their specific communication skills [38].

There are, of course, a non-trivial number of simulations in these platforms. The majority of them is relevant to integrated medical awareness building for students (eg, Ohio State Medical Center, a virtual place for educational purposes [39]) and for postgraduates (eg, Wiecha et al [40]). There are, furthermore, even more specialized simulation environments such as a transfusion operation simulator [41], or a human immunodeficiency virus (HIV) epidemic simulator [42] as well as other hazardous or highly impactful real life situations [43], [44]. Even in a rather narrow and specific healthcare field such as dentistry there have been some activity ([45]-[49]) but with the bulk of the activity turned towards proprietary custom virtual reality simulators ([50]-[53]).

Due to its highly collaborative nature and the ease of content creation in these platforms, nursing training has a strong presence in them. There are several studies and reviews regarding nursing education ([54]-[59]), ranging from generic journal clubs [60], honing interpersonal interview skills [61] and decision-making capabilities [62], to specifics like mental health nursing [63], moving all the way to meta-education, such as faculty education about nursing teaching methods [64].

With this being only a very high level overview of the material available on these platforms and a couple of very comprehensive cataloguing efforts [18] [65] the overall aim of this discourse is to demonstrate the significant research interest in experiential medical education as it stems from medical education's necessities of learner 
engagement and immersive and integrative learning experience.

This work is a follow-through of current achievements in our VP repurposing efforts into the OpenSim (OS) MUVE. With an established streamlined way of presenting VPs in this environment in the context of point and click adventure episodes [49] we present here a further automation of this presentation method. First we present as it has been achieved, the separation of the narrative from the virtual environment and its consumption from the web using static web page tree as a proof of application approach. Then we present a data scheme for facilitating the automation of this process through established contemporary ICT methods. Finally we present a high level conceptual architecture of a system that would utilize these provisions and implement the whole of the repurposing effort. Closing, implications of this work and further future directions are discussed.

\section{Implementing VP repurposing.}

The VP repurposing as it is described in this work consists of several cumulative steps that build on each other and lead to the conceptualization and proposition of this work's processes. As can be seen in Figure 1 from prior repurposing contexts (described in 2.1) an expansion of scope initially leads to the transfer of web based VPs to a MUVE (described in 2.2). The streamlining of this process leads to the incorporation of web based metadata to specific but generic 3D assets in the MUVE (described in 2.3). This methodology evolved into the OSCase data scheme (described in 2.4). The implementation of this data scheme (described in 2.5) is the distilled core outcome and key repurposing enabler for Virtual Patients in 3D environments.

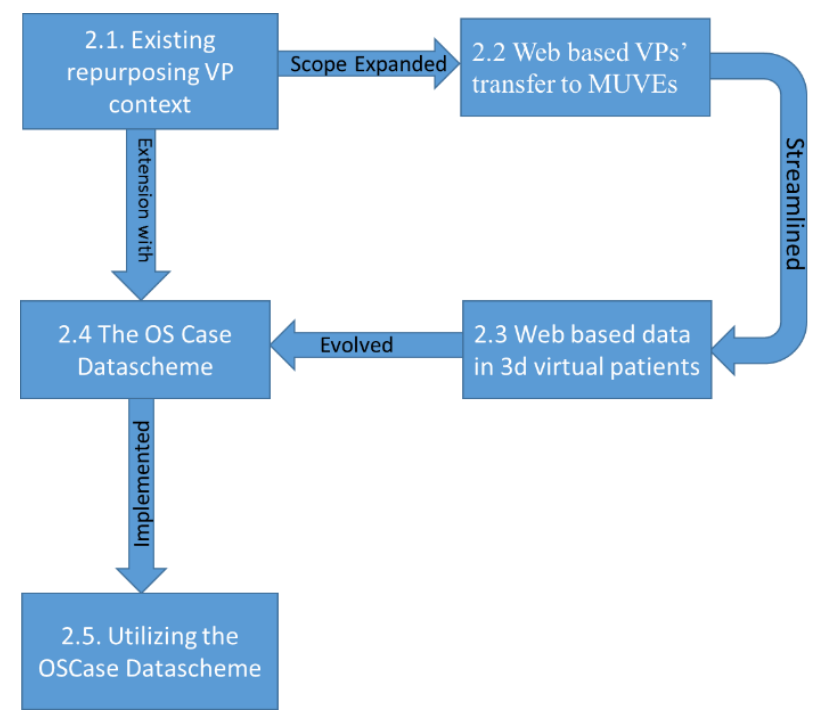

Figure 1 Process diagram of the VP's repurposing conceptualization

\subsection{Repurposing VPs; context}

The efforts taken are founded on the contextual repurposing work that has been done through an extension of the mEducator metadata scheme [49], [67] as it was implemented in OpenLabyrinth in order to create its semantically enriched extension, OLabX. This work provides search, share and description capacities, for repurposing and reusability to the platform. The OLabX extension contains metadata descriptions of the virtual patient's narrative tree (Labyrinth) utilizing the already existent OLab Global Metadata Editor. A conceptual example of such a VP tree (Labyrinth) is demonstrated in Figure 2.

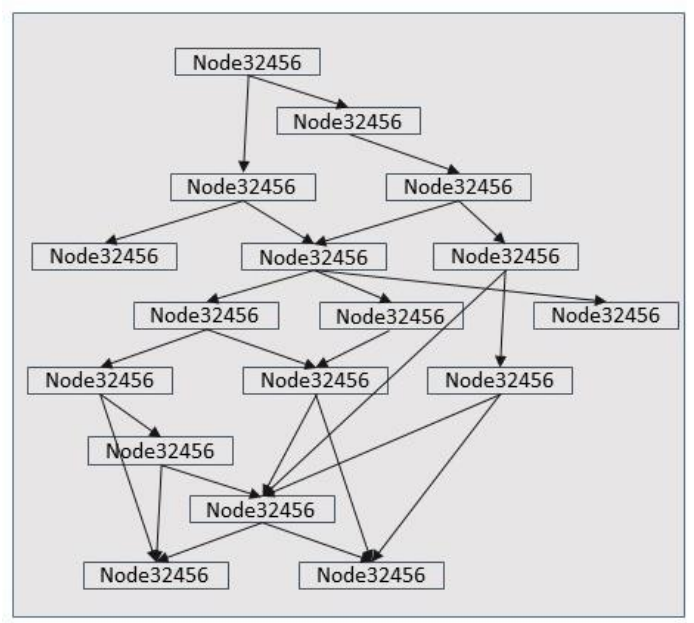

Figure 2 Node Link example of a virtual patient tree. The Nodes (boxes), contain the narrative elements of the VP. The links (arrows) provide the interactivity of the case by describing plausible links between Nodes (via text or other methods of interaction)

This way it is coherent with the provisions already existing in the core mEducator schema. This schema $(\mathrm{OLabX})$ provides a metadata definition that accompanies the educational resource [49] (the VP), that is highly structured in order to facilitate resource reusability and repurposing [67]. It is also implemented so as to provide advanced repository functionalities that are not present in the core OLab tool. These include contextual content query, with synonym identification, as well as rudimentary analytics in the form of past user preferences. These features of OLabX both separate it from the core version but also provide the contextual background in which the repurposing to MUVEs is implemented. Adding in this the scheme's open architecture through established existing vocabularies (a feature ensuring OLabX's extendibility through implicit RDF referencing, for details cf [14]) it provides an even more rigorous set of constraints for streamlined MUVE transfer facilitation of VPs

\subsection{Web based VPs; transferring to MUVEs}

The efforts taken for transferring virtual patients on different presentation platforms consist of the "crossenvironment" migration of VPs from the Web to MUVEs. Beginning with a simple manual transfer these repurposing efforts included both a dental VP [49] and initial cases for training scenarios of elderly care training [68]. While the 
subject matter was in widely different areas of the overall healthcare field, the technical specifics were the same. The cases were deployed initially in Second Life and then in OS both in the form of a point-and-click adventure. User feedback was provided mainly through chat messages. The user guided the action through either multiple choice notecards on which she was able to make her choices or through simple item choice (Figure 3), by clicking on them, at which point the user declared her intended action as described by the cases' narrative (Figure 4). In all cases the VP trees were implemented to the OS MUVE verbatim as they were initially deployed in OLab. Gamification constraints (time limits, grading for quality of choice) were removed because the focus was on the assessment of implementation and usability and not in the efficacy of the case as an evaluation tool. Almost all the choices made by the player, were narratively evaluated in the case, with the user being provided with opportunities to retry in order to avoid unnecessary frustration.

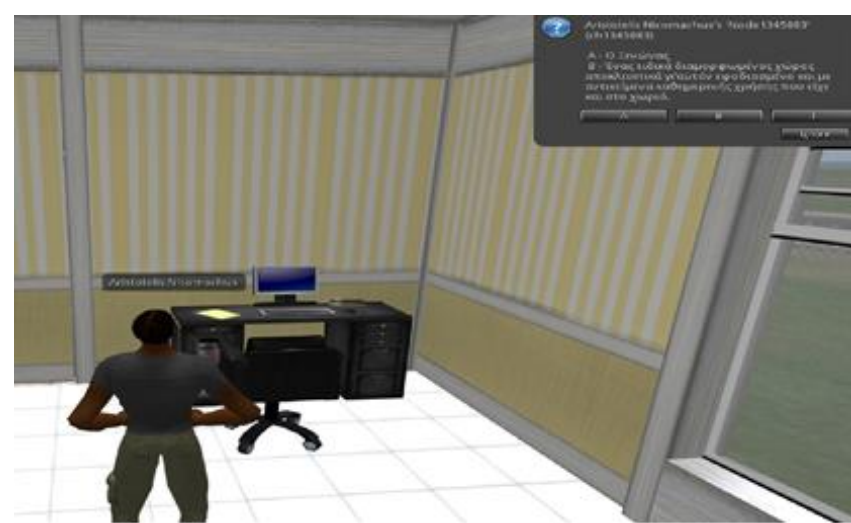

Figure $3 \mathrm{~A}$ multiple choice notecard for receiving the input of the user in OpenSim deployed VP; elderly care training scenario. The user is called to choose the best way to host an increasingly sedentary elderly relative (choice between a- the guest room and b- a specially prepared familiar looking personal space)

Technically, all the simulation of the virtual patient activities was implemented through the OpenSim Scripting Language/Linden Scripting Language (OSSL/LSL). All the appropriate Web resources (e.g., images) were stored in a lab server. OSSL/LSL are event/state-based languages. Scripting utilizes events, such as clicking, listening for chat messages, or deploying items in the world. Using these as trigger events complex scenarios of interactivity and action can be coded. Such case activities were implemented as events, triggered as the user interacted with the simulation by touching (clicking) pieces of the environment and receiving challenges in the form of multiple-choice questions. The user's response triggered additional events that led the case to move to the next relevant state/node.

At this stage, all the narrative, patient data values, or external media references were stored in the case script as global variables. Each object in-world contained its script, one that communicated with a set of main simulator scripts in order to facilitate interaction through clicking on objects. In order for this model to cater for technical limitations (e.g. maximum script file size) as well as following OLab's implementation logic, virtual "nodes" were created in OS/SL (OpenSim/Second Life) too. These were, in-world, intangible (i.e. non interact-able/non collide-able), invisible objects, containing scripts that implemented all the connectivity logic and presented the case's narrative to the user.

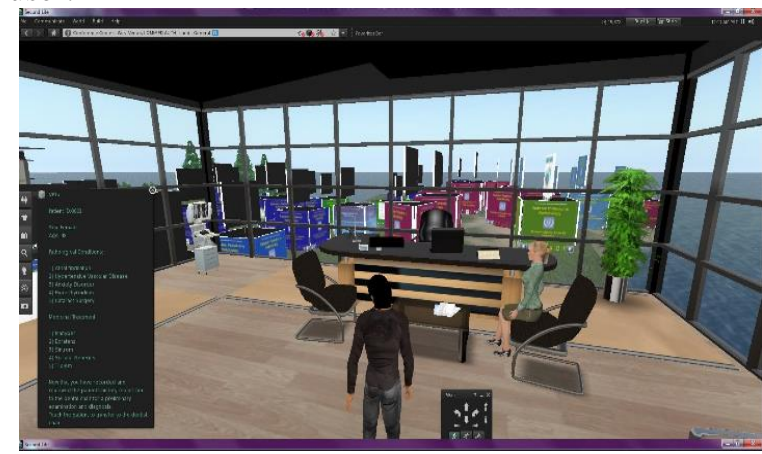

Figure $4 \mathrm{~A}$ point and click selection instantiation for driving the case in a Second Life deployed VP; Dental training scenario. The user is presented with full clinical details (Reason for seeking medical expert, full history and medication)

Communication between these nodes was realized through simple chat message exchange in predetermined chat channels of OS/SL. Regarding the user experienced, each case was experienced as an interactive point and click adventure receiving feedback and making choices, with the selection and clicking activities being an interactive navigation of the virtual node tree (that was transferred to the simulator) through clickable objects and multiple choice notecards. All scripting nodes consisted of one of these two script types and between the nodes of the same type differences existed only in variable values (narrative strings, navigation node id numbers etc). Thus, from a technical point of view, implementation time was reduced and debugging was facilitated as far as could be given the scripting environments simple debugging capacities. Specifically, while the first, unoptimized virtual case was implemented in the span of 80 person hours, the design optimized case was implemented in 36 person hours. Furthermore this implementation ensured maximum reusability of script assets and also presented the practical context for both implementing a data scheme and an implementation architecture for automated deployment of OLab VPs in OS.

\subsection{Web based data in 3D virtual patients.}

In order to evolve the architecture and the data scheme that would facilitate repurposing of web based VPs in a 3D virtual environment a standard serialization for the description of this VP in the context of a standard OS point and click VP "adventure" was developed. To test this prototype serialization, a tree of static webpages containing a whole virtual case was created. For all intents and 
purposes these static web pages were placeholder for the dynamic web page that should substitute them in a contemporary implementation architecture that will be described below. The goal was to ascertain that both viewer capacities and VP modelling were able to be encapsulated in web transferable serializations.

The OpenSim implementation of the VP viewer consisted of creating a generic medical 3D environment (cf. Figure 5). In it object scripts were set up in each interactable object (cf.

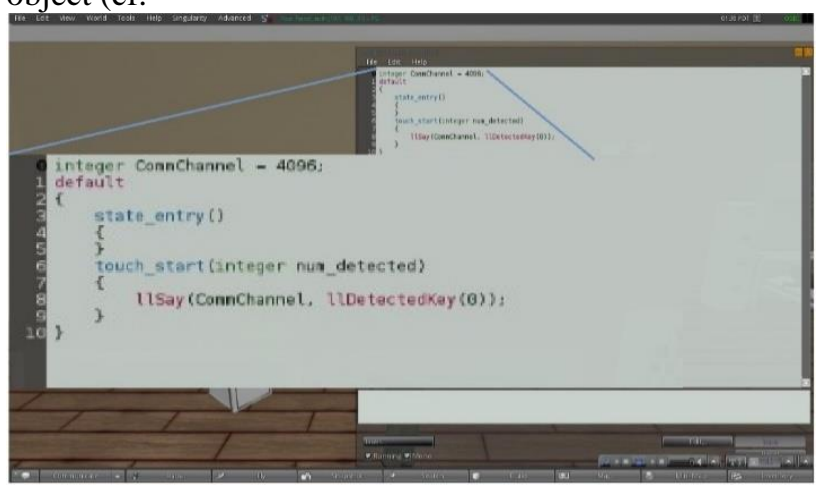

Figure 6). These script differed, in each object, only in the UUID key that was identifying the specific object. These keys were incorporated manually in the data serialization of the relevant node web page. In that way, the interaction with the environment's objects at each stage of the VPs execution was identified and meaningfully consumed from the viewer to the relevant web page VP node serialization.

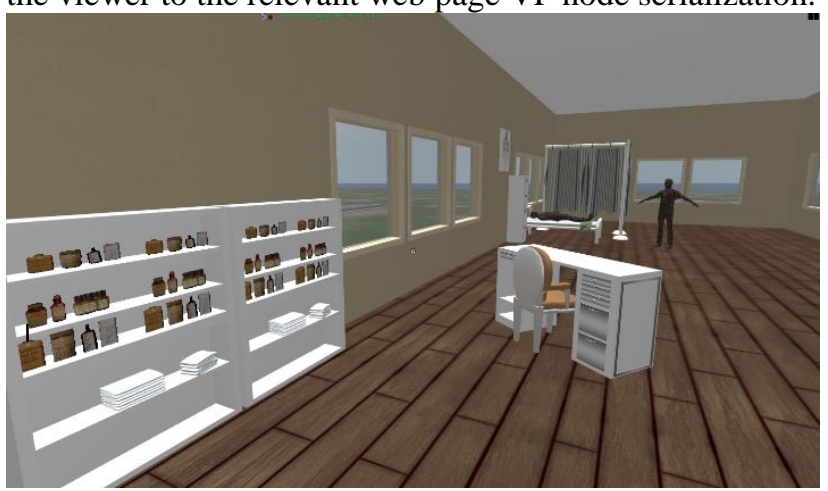

Figure 5 All-purpose medical 3D environment

To realize this interaction, a core viewer script was implemented (Figure 7) that (at this prototype stage) pointed to the initial VP node and consumed all serialized data. This viewer script provisioned for all expected interactions in the virtual environment such as Notecard multiple choices (Figure 8) and point and click interaction (Figure 9). Beyond that, a central viewer script was implemented that parsed each relevant serialized node (in the form of the prototype web pages). Each web page (cf. Figure 10) contained the links to the next in order to separate the viewer logic that was implemented in the OSSL script from the VP logic that was implemented in the serialized data structures of the static web pages.

The body of the web pages was a prototype JSON data encapsulation (cf. Figure 11) in order to prototype the communication of the OSSL with the web pages.
The goal of the design of the JSON serialization that was tested in the static implementation of the prototype OS viewer was to implement a data model that can be used for all kinds of interaction while at the same time remaining open to contain more functionalities in the future or even shift to a different gamification format or platform.

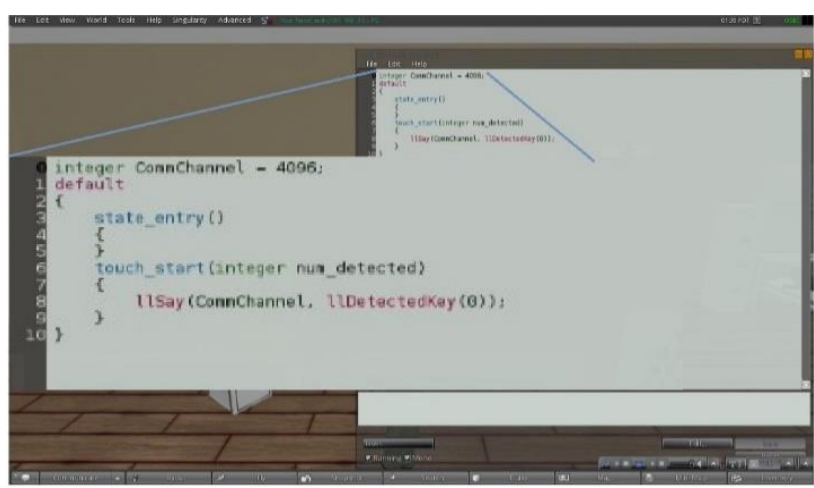

Figure 6 Each object in-world only communicates its interaction with the user.

That is why the data serialization was specifically split between viewer relevant stuff (e.g IsSingleAsset denotes that this node choices should appear in Notecard if true, or LinkAssetUIDs that is the OS objects' unique identifiers) and the VP relevant stuff (e.g NodeText which is the text that narrates this nodes situation or LinkTexts that refers to the texts that accompany each choice). The details of the serialized data structures are summarized in Table 1

Table 1 Data structures contained in the JSON VP data serialization.

\begin{tabular}{|c|c|c|}
\hline $\begin{array}{l}\text { Table column } \\
\text { heading }\end{array}$ & $\begin{array}{l}\text { Data } \\
\text { Structures } \\
\text { Scope }\end{array}$ & Description \\
\hline IsSingleAsset & OS Viewer & $\begin{array}{l}\text { Flag to identify } \\
\text { notecard interaction } \\
\text { nodes }\end{array}$ \\
\hline LinkAssetUIDs & OS Viewer & $\begin{array}{l}\text { Array of OS UUIDs } \\
\text { that are relevant to } \\
\text { this node' }\end{array}$ \\
\hline LinkUUID_xx & OS Viewer & $\begin{array}{l}\text { OS Object UUID that } \\
\text { activates the } \\
\text { enumerated link of this } \\
\text { node }\end{array}$ \\
\hline Nodeid & VP model & Id number of the node \\
\hline NodeText & VP model & $\begin{array}{l}\text { Narrative text of the } \\
\text { node }\end{array}$ \\
\hline LinkNumber & VP model & $\begin{array}{l}\text { Number of links in the } \\
\text { node }\end{array}$ \\
\hline Linklds & VP model & $\begin{array}{l}\text { Array of linked } \\
\text { nodeids }\end{array}$ \\
\hline Link_xx & VP model & $\begin{array}{l}\text { Nodeid of enumerated } \\
\text { link }\end{array}$ \\
\hline LinkTexts & VP model & $\begin{array}{l}\text { Array of narrative text } \\
\text { of links }\end{array}$ \\
\hline
\end{tabular}




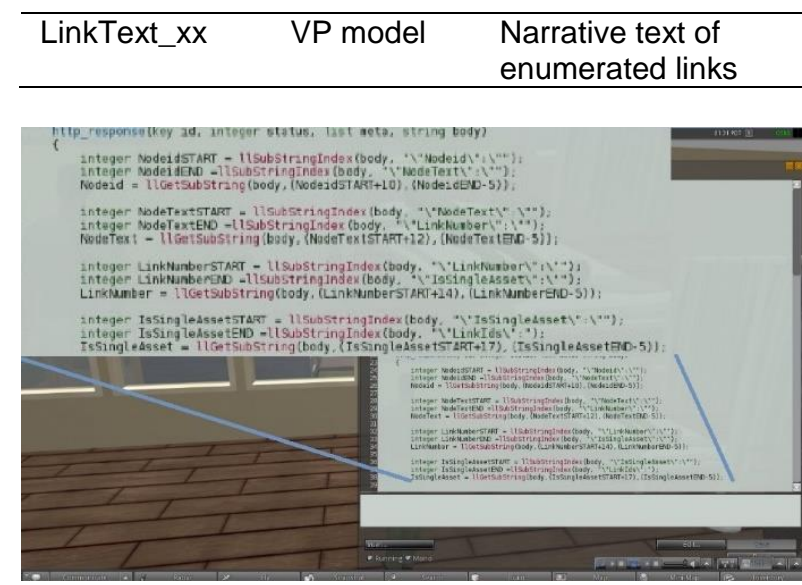

Figure 7 The main OSSL script points to the Virtual Patients initial page. Interactions and logic is implemented in the web page node description. The main OSSL script is a parser for the serialized content from the web page

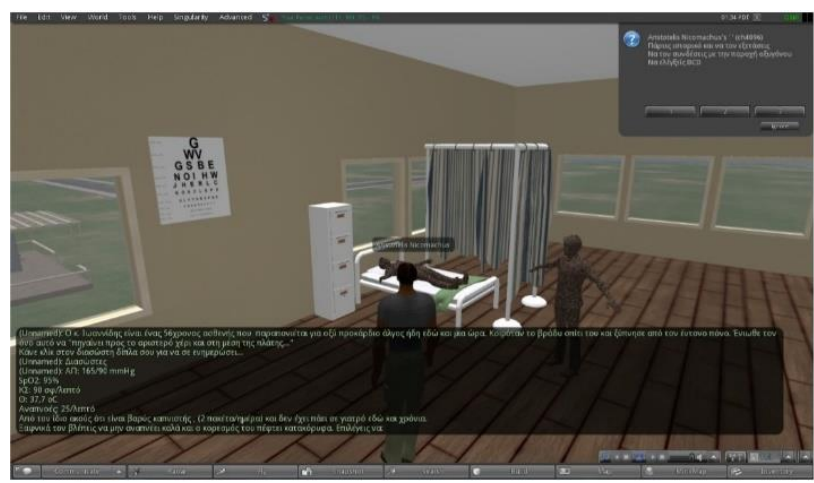

Figure 8 The main OSSL script facilitates notecard multiple choice selection. The number and type of selections is stored in the web pages. Current node presented includes detailed narrative about the patient's history and the choices available to the user.

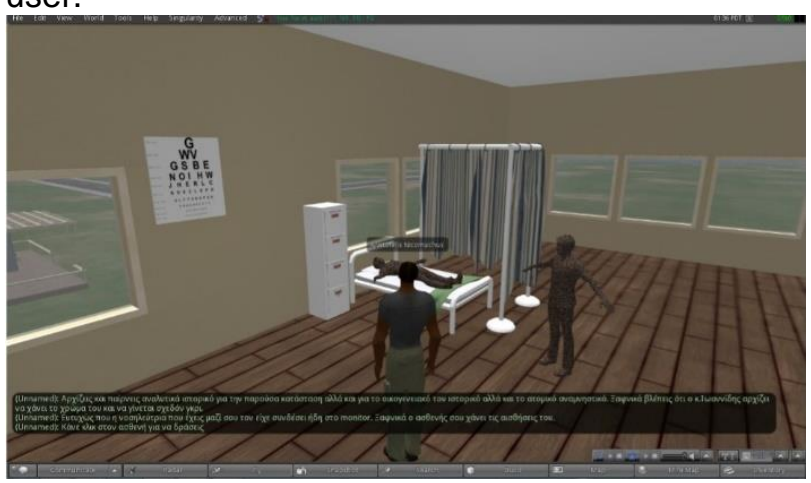

Figure 9 The main OSSL script facilitates object interaction for VP path selection. The type of selection (multiple choice or object interaction) is stored in the web pages modelling of the VP nodes. Current interaction with the patient narrates his loss of consciousness due to an inappropriate prior user choice.

\subsection{The OS Case Datascheme}

In the previous sections the repurposing of VPs from the web to the MUVE, as well as the streamlining of their data serialization has been described to provide context to the effort being made currently to automate the transfer and linking of OLab resources to the OS MUVE.

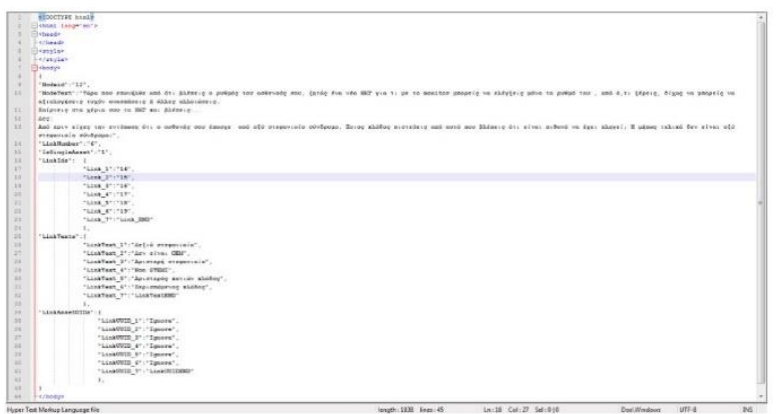

Figure 10 Node Web page containing all the necessary info for OpenSim to act as a VP viewer. Details of the content serialization are presented in Figure 11.

The overall approach of the OS Case Datascheme is outlined in Figure 12. Each OS Geometry Object is defined as the actual graphical asset, e.g. a house, a chair, etc as depicted in-world. This becomes part of the OS Asset Repurposing Archive and is assigned, through the OS Object datascheme the necessary attributes for unique identification. These include the URL of the Grid in which it belongs, its unique in-world identifier - OS - UUID, OS Grid geometry localization (where it is and its dimensions) as well as a designated channel that will be used for communication with this asset. Geometry Objects are distinguished between Assets and Environments in order to establish a basic hierarchy (e.g. a piece of Furniture is an asset that belongs to the Environment "Beach house") that can be used by content creators for meaningfully interpreting relationships between Assets. For example, if a user was to repurpose a VP and choose as environment a "Doctor's Office" there should be clarity about which assets of the database are technically, in the same OSGrid and, thus, physically within the environment. This OS Object datascheme is incorporated to the overall OS Case datascheme which also links to OLab's datascheme in order to facilitate the assignment of meaningful state/link pairings to each instance of use for each OS Asset that is utilized in the repurposing effort. Each of the significant entity types in OpenLabyrinth has its equivalent in OS. For this purpose, the data scheme includes classes like Labyrinth, Node and Link, which represent the same structure found in the original virtual patient. The mapping between the OpenLabyrinth entities and the OS Assets is realized through a set of interaction-related classes. NodeNavigation is a wrapper around Node. An instance of this class is created every time the user navigates to a new node by following a link.

The NodeNavigation instance is followed by an InteractionTriggerCollection which represents the outgoing links of the current node, introducing interactivity. Depending on the semantic properties 
embedded into the node, the InteractionTriggerCollection instance is implemented either as a NoteCardOptionCollection or a LinkBoxCollection to address the scripting implementation of either Notecard or clickable objects' nodes. The former is attached to an OS asset that triggers it and is followed by many NoteCardOption instances to show as message options in the OS Notecard.

LinkBoxCollection, on the other hand is not attached to a specific asset, as it is followed by LinkBoxes that each is attached to the relative triggering asset (OS Clickable object). Both LinkBox and NoteCardOption can be seen as parts of an interaction setting where they are expressing the multiple navigation paths available starting from a labyrinth node. All communications between the MUVE and the web infrastructure shall be realized in JSON format The detailed description of the OSCase datascheme in UML is presented in Figure 13 -Figure 15.

\subsection{Utilizing the OSCase Datascheme}

The previously described OSCase data scheme design was used as a guide for implementing a specific architecture of repurposing VPs in 3D Virtual Environments. As was mentioned above, the OSSL Scripting base that can make HTTP requests passing variable arguments and receiving limited HTTP content (Text or links to rich resources) is already available. Additionally, as was also demonstrated above, through a proof of application implementation, there is a viable VP/MUVE data serialization that can be pulled and pushed from static web pages. Finally the content repository and relevant logic as a VP model are already well established even as formal standards [8].

The logical step in this context is a web layer that will publish a dynamic web page that shall be the repurposer's exposed API for the virtual environments that are going to be used. Furthermore, in this web layer a repurposing front end is required to provide the functionality of linking the VP content as it stands in the web with the details of the specific virtual environment.

Essentially the requirement is for a middle layer between the dynamic web publication and the VP model that is reposited in the back end. This is facilitated through separate but inter-supported web services for the functionalities that are exposed in the web front end. The aim was to avoid having separate data bases for each virtual environment that might be used, but also be able to utilize the same web based VP content in various development platforms. We maintained the independence of the whole presentation side (3D environment and web front end) from the educational VP model.

The middle layer envisioned for connecting the whole presentation end to the VP model, while not exactly interconnected acts as a transparent bridge between independent but relevant layers. This context provides the necessary provisions needed and the required design paradigms that need to be implemented. Having these data scheme provisions and the aforementioned web based data serialization scheme, an architecture for implementing these capacities has been devised. This architecture is demonstrated in Figure 18.

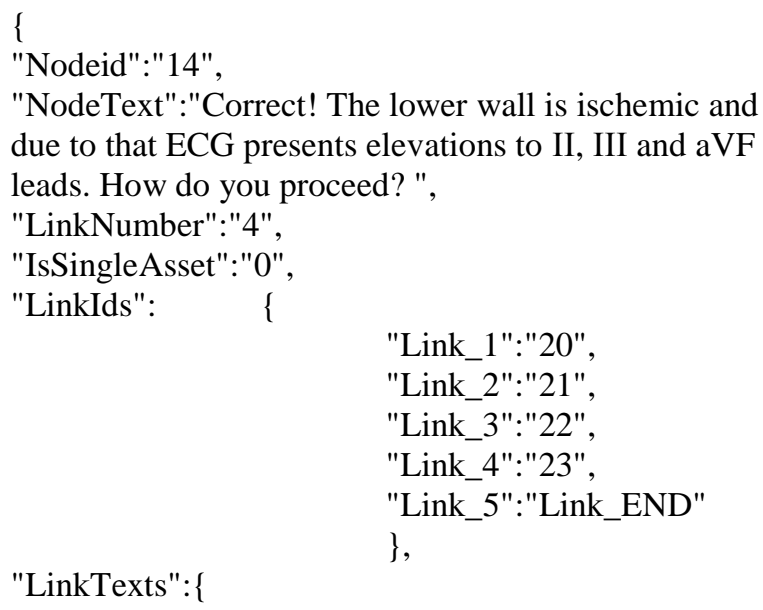
shelf next to the bed to provide medication and then to talk with the Haemodynamics laboratory.",

"LinkText_2":"Click to your office so that you can schedule a coronary angiography.",

patient to perform thrombolysis. ",

"LinkText_3":"Click to the

"LinkText_4":"Click to the paramedic to order troponin and follow through in 12 hours. ",

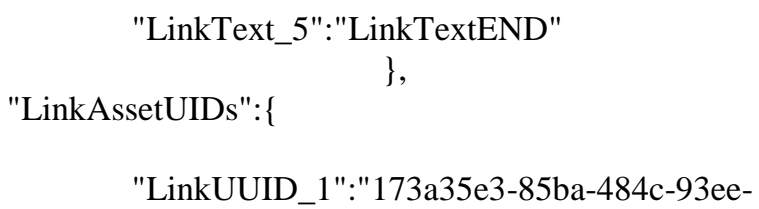

Figure 11 JSON serialization of VP node data and relevant $O S$ viewer information

In this architecture, the OSSL scripting layer communicates with a dynamic web page that provides the appropriately serialized educational VP content. While this implementation demonstrating this architecture through OSSL scripts, (as this is the current virtual environment that is utilized) this is not a hard requirement. Any 3D game 
engine or environment that has scripting provisions able to make POST/GET HTTP requests, passing the necessary arguments is a viable candidate for implementation in this architecture.

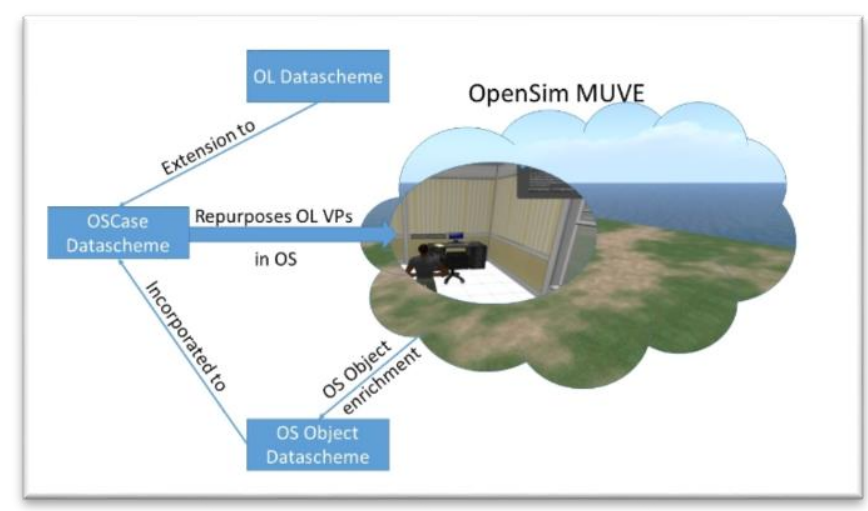

Figure 12 The overall approach of the repurposing effort from OLab to OS.

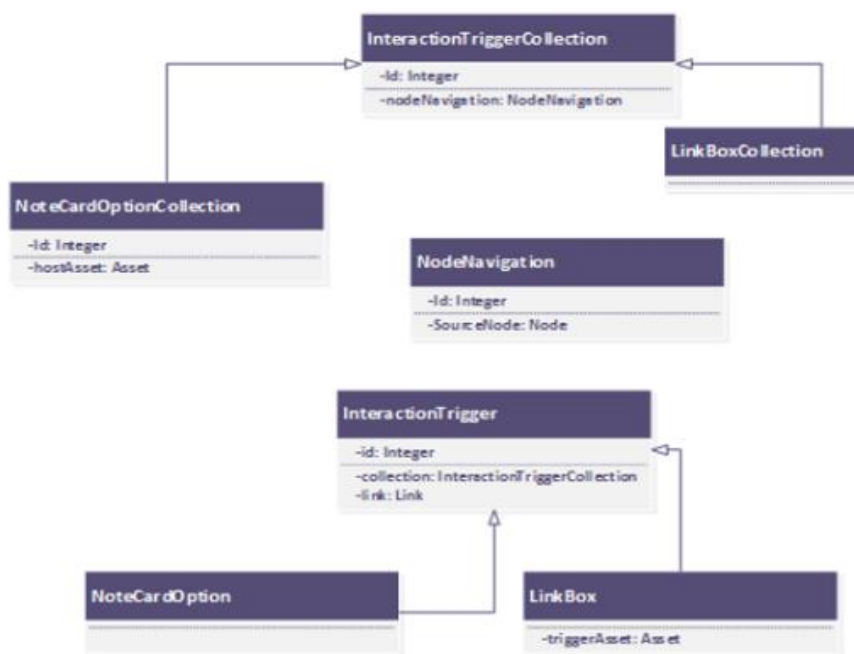

Figure 13 OSCase Datascheme A: The Relationships of the proposed datascheme.

The web front end of this implementation is a user interactive MUVE-content annotator (For a mock-up of the proposed front end cf. Figure 17). In this the user is presented with an interactive view of the VP's narrative tree with its nodes and links. Additionally, the OSCase data scheme's provisions for annotating and archiving the inworld position relative to the overall environment must be used to create a $2 \mathrm{~d}$ layout of the place with all OSCase registered geometry presented with spatial accuracy. The workflow of this front-end consists of the user linking the virtual patient's nodes and links to specific parts of the environment's geometry so that they correctly associate and trigger navigation through the case tree in the simulator. Additionally, editing capacities are provisioned in this front end for the case's narrative to be adaptable to the permutations that shall be necessary due to the presentation platform repurposing. This front end is linked to the rest of the architecture through a couple of enabling web services.
The first encapsulates and passes the scripting arguments as they are communicated through the virtual environment's scripting to the implemented VP model.
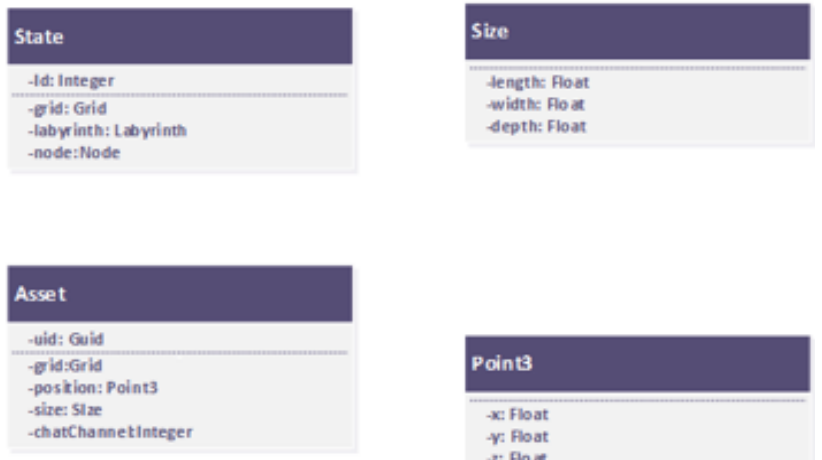

Figure 14 OSCase Datascheme. B: OpenSim side Description.

Additionally it receives the VP model's resources and serializes them according to the previously described data model in order to be consumable from the VEs scripting infrastructure. To accomplish that it utilizes the OSCase's data scheme for data integrity between the database infrastructure, web interface and OS/SL presentation layer (Figure 18).
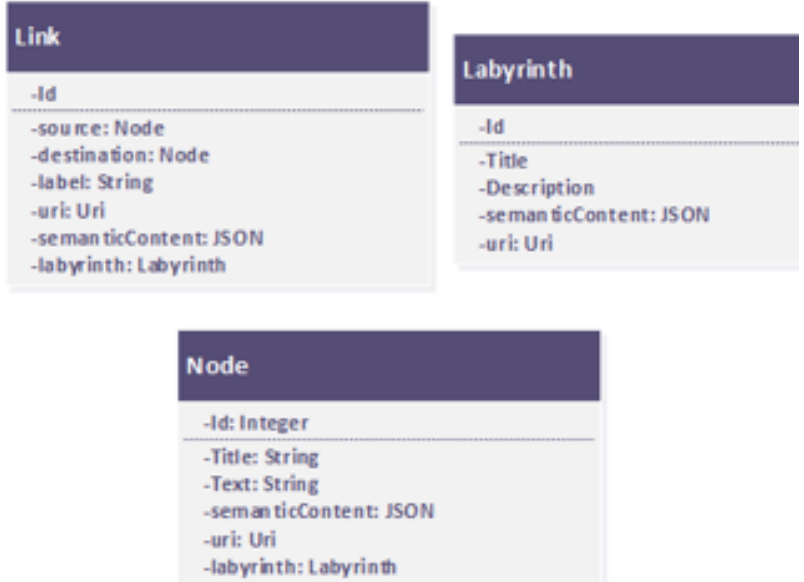

Figure 15 OSCase Datascheme. C: OLab-side inclusions.

Second an aggregation and repurposing web service is provisioned. This would consume the outcomes from the user interactions in the VP repurposing front end reposit them in the database infrastructure and create aggregate educational content in the form of linked 3D assets and virtual patient nodes that would be usable in the $3 \mathrm{D}$ environments. Again in this web service, communication and data integrity is maintained through the use of the OSCase data scheme (Figure 19). 


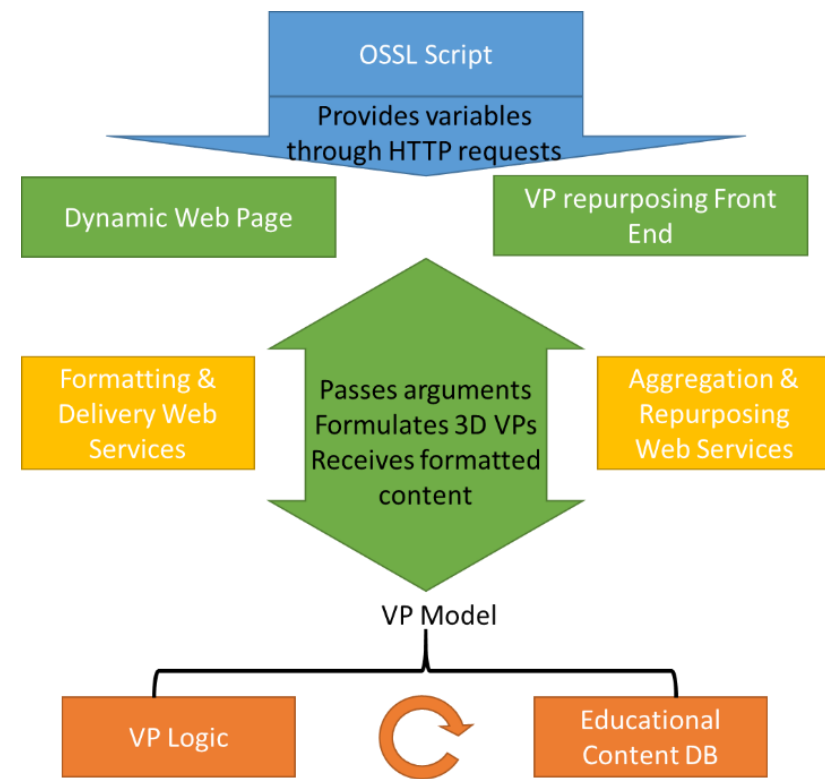

Figure 16 OSCase implementation Architecture.

It must be noted here that it is a conscious architecture choice to reposit the details of 3D assets that are used in the 3D environment, and implement their links on an "as needed" basis. Since we aim for maximum repurposability we need to have a reference to the 3D objects (UUID, or even file) and its link relevant to various nodes of a VP as separate entities but in the same educational repository. That way, assets can be both discoverable but also independent from VP node content while facilitating repositing and dynamic formulation of platform specific VP nodes for 3D environments.

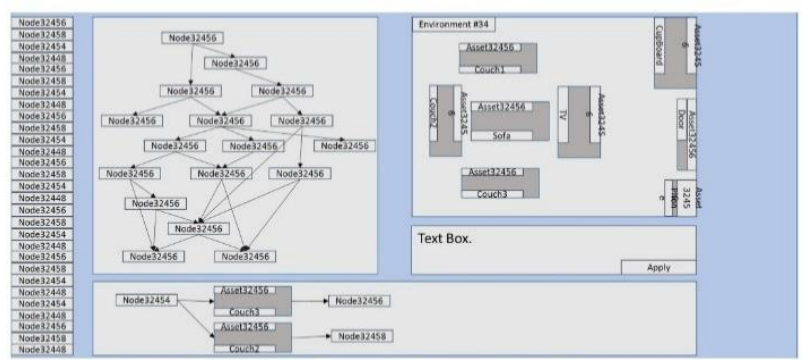

Figure $17 \mathrm{~A}$ mock-up of the front-end required for repurposing VPs for OpenSim consumption.

\section{Discussion}

Content generation efforts in experiential 3D environments are not of course novel. Especially in presentation heavy fields such as cultural heritage, there have been several endeavours of migrating to 3D environments of real-world cultural content (eg, depictions of works of art, monuments etc. [69],[70]). In that field also there have been successes in the use of semantic annotation and content enrichment of that content in order to streamline the transfer to the virtual from the real world [71]. Metadata, embedded from wikis and well established semantic namespaces, together with geospace information, have been successful used for providing real-time automated updating of $3 \mathrm{D}$ environments based on real-world cultural heritage sites [72].
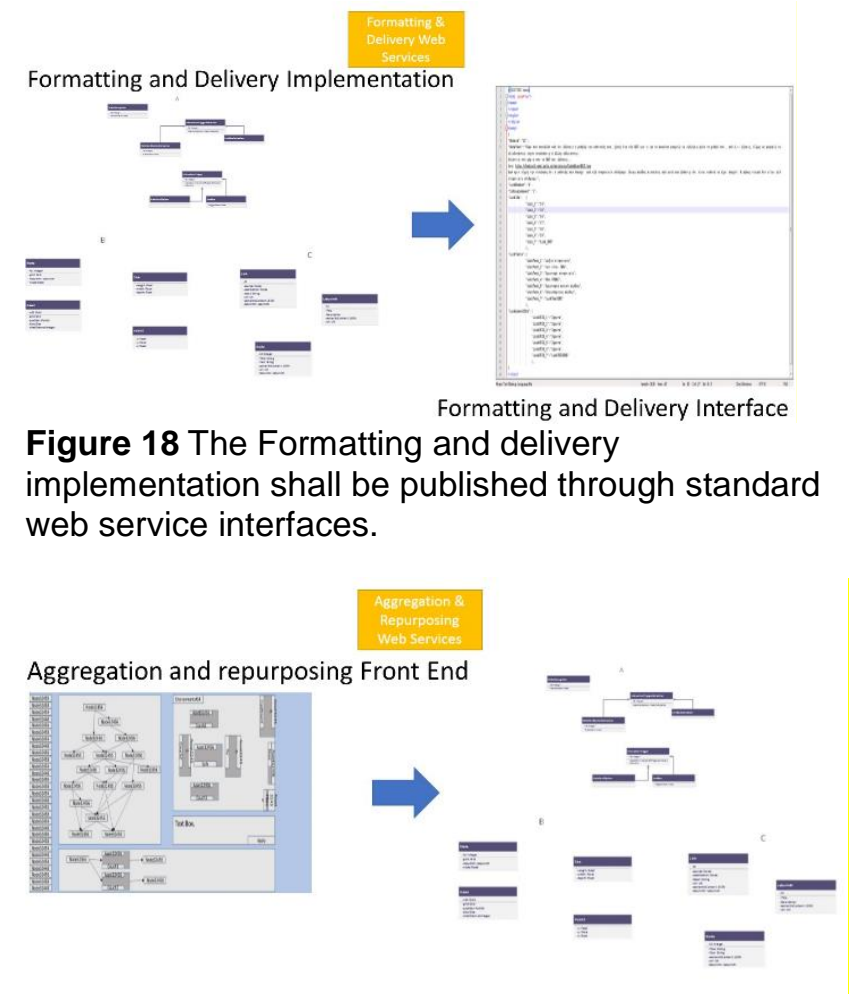

Aggregation and repurposing Implementation

Figure 19 Aggregation and repurposing front end shall utilize the data model implementation for streamlined annotation and repurposing.

Moving to medical education, and before engaging academic teams and infrastructures (eg, Health Sciences administration structures) in such efforts, there must first be an investigation on suitability of the incrorporated learning content. It is certain that the incorporation of web based virtual patients in medical curricula is not a novelty; there have been studies of their impact and effectiveness as course materials [73],[74]. Furthermore, with the transition from the Web to the virtual environment not a pedagogically straightforward one there have been the need to explore the necessities of the MUVE platform through user feedback. In that area, previous works have put forward [49] the guidelines and best practices regarding appropriate and pedagogically correct repurposing of the virtual patient content from the Web to a 3D MUVE. However, moving to the technical specifics of the aforementioned efforts, on an attempt to incorporate the 2 aforementioned axes of research, the virtual patient repurposing from the Web to the $3 \mathrm{D}$ virtual environment and the automation by semantification of content generated in $3 \mathrm{D}$ virtual environments, the present work aims to provide a credible proof of concept, with key implemented components, for a framework that can incorporate these media and standards' advances. This is the key original and unique feature of this current work. In short, the presented work describes a system that can be readily utilized for 
transferring and streamlined repurposing of OLab deployed VPs in the OS/SL MUVEs. At the moment the implementation focus is on the previously described web based front end and web services. These will allow experts and other content providers to rapidly repurpose VPs into the MUVEs. Immediate future steps after the implementation endeavour include both efficacy and usability testing of this repurposing framework.

Moving beyond just an experiential shift, the phrase Virtual Learning Environment (VLE) in online education has significantly shifted its meaning. From discrete, closed online repositories where instructors uploaded content through strict access management terms, to a world of today's Massive Open Online Courses (MOOCs) [75] VLEs are now envisioned as decentralized, collaborative, educational activities' signposts that guide, albeit expertly, the participant to find appropriate content for organically achieving specific learning objectives. With a mature standards space VLEs can leverage streamlined data modelling and implementations. For example, the Sharable Content Object Reference Model (SCORM), which consisted of a collection of standards and specifications aiming to facilitate standardized content packaging, delivery, and consumption [76] is a first layer of content abstraction with the aforementioned Medbiquitous VP standard being a more topic specific second. In this standards space, content is envisioned to be delivered through an online toolset infrastructure [77], also decentralized and utilizing the cloud [78]. The learner is an active collaborator and can become an activity hub if her content acquires enough significance or peer acceptance. For example, while the educational process may begin in the central MOOC hub, the core of collaborative educational action may shift to a student's personal blog or youtube channel [75].This decentralized learning content paradigm aligns well with the repurposing effort that the presented work aims to support. With the immersion potential, the capacity for collaboration and engagement of MUVEs as a given [17], [18], the possibility of inclusion of this educational medium in Massive Open Online educational endeavours seems a natural next step. Thus streamlining transfer of such cases to a MUVE can provide a significant content boost in MUVE VPs. With the aforementioned decentralization of the infrastructure, the integration problem becomes less important and the main barrier becomes the creation and availability of non-trivial amount of quality content. With web based VPs as an implemented learning tool being around for some decades [79] and OLab almost reaching a decade of existence [11] the practical implications of the presented work as a means for the availability of non-trivial quality content through reuse and repurposing, at a highly granular level of existing VP content achieves an increased level of significance. The potential for a technological infrastructure that shall be able to consume web based, appropriately annotated virtual patients and then procedurally create the $3 \mathrm{D}$ environment in which to experience them is a long term goal that this works seeks to facilitate. Furthermore, this work is a step in an evolving endeavour towards streamlined repurposing of VPs into MUVEs and in integrating this medium in the overall effort of contemporary VLEs. With the feasibility of deploying web based VPs in VLEs such as MOOCs having been explored with promising results [80], [81] a future direction to be explored after full technical implementation and evaluation is the attempt at transparently offering experiential 3D content in the context of a MOOC VLE.

\section{References}

[1] M. Schittek, N Mattheos, H.C. Lyon, R. Attström, Computer assisted learning. A review. Eur J Dent Educ 2001 Aug;5(3):93-100.

[2] H. Fry, S. Ketteridge, S. Marshall, A Handbook for Teaching and Learning in Higher Education:Enhancing Academic Practice. 3nd edition. New York, Md: Routledge; 2009. ISBN: 0-203-89141-4 Master e-book ISBN

[3] S. Downes, Distance Educators Before the River Styx Learning. $2001 . \quad$ URL: http://technologysource.org/article/distance_educators_bef ore_the_river_styx/. [Medline: 11520331]

[4] E. Kaldoudi, S. Konstantinidis, P. Bamidis, Web 2.0 Approaches for Active, Collaborative Learning in Medicine and Health, Chapter. In: S. Mohammed and J. Fiaidhi editors. Ubiquitous Health and Medical Informatics: The Ubiquity 2.0 Trend and Beyond. USA: IGI Global, Hersey; 2010 (ISBN: 978-1-61520-777-0)A.N. Author, Book Title, Publisher Name, Publisher Location, 1995.

[5] R. Ellaway, C. Candler, P. Greene, V Smothers, MedBiquitous. 2006. An Architectural Model for MedBiquitous Virtual Patients URL: http://groups.medbiq.org/medbiq/display/VPWG/MedBiqu itous+Virtual+Patient+Architecture

[6] R. Ellaway, T. Poulton, U. Fors, J.B. McGee, S. Albright, Building a virtual patient commons. Med Teach 2008 Jan;30(2):170-174. [doi: 10.1080/01421590701874074] [Medline: 18464142]

[7] MedBiquitous. Standards URL: http://www.medbiq.org/std_specs/standards/index.html

[8] MedBiquitous Virtual Patient Summary. 2010. URL: http://www.medbiq.org/working_groups/virtual_patient/M edBiquitousVirtualPatientSummary.pdf

[9] T. Poulton, C. Balasubramaniam, Virtual patients: a year of change. Med Teach 2011;33(11):933-937. [doi:10.3109/0142159X.2011.613501] [Medline: 22022903]

[10] H. Salminen, N. Zary, K. Björklund, E.Toth-Pal, C. Leanderson, Virtual patients in primary care: developing a reusable model that fosters reflective practice and clinical reasoning. J Med Internet Res 2014;16(1):e3 [FREE Full text] [doi: 10.2196/jmir.2616] [Medline: 24394603]

[11] R. Ellaway, OpenLabyrinth: An abstract pathway-based serious game engine for professional education. In: Proceedings of the Fifth International Conference on Digital Information Management (ICDIM). 2010 Jul 05 Presented at: Fifth International Conference on Digital Information Management (ICDIM); July 5-8, 2010; Thunder Bay, ON.

[12] http://openlabyrinth.ca/wpcontent/uploads/2013/04/OpenLabyrinth-v3-UserGuide.docx

[13] Round J, Conradi E, Poulton T. Training staff to create simple interactive virtual patients: the impact on a medical 
and healthcare institution. Med Teach 2009 Aug;31(8):764769. [Medline: 19811216]

[14] Calinici T, Muntean V. OpenLabyrinth-A Web application for medical education using virtual patients. Appl Med Inform 2010;27(4):15-20.

[15] E. Dafli, P. Antoniou, L. Ioannidis, N. Dombros, D. Topps, \& P.D. Bamidis. Virtual Patients on the Semantic Web: A Proof-of-Application Study. Journal of Medical Internet Research, 17(1), e16. (2015)

[16] Gesundheit N, Brutlag P, Youngblood P, Gunning WT, Zary N, Fors U. The use of virtual patients to assess the clinical skills and reasoning of medical students: initial insights on student acceptance. Med Teach 2009 Aug;31(8):739-742. [Medline: 19811211]

[17] L. Papadopoulos, A.E. Pentzou, K. Louloudiadis, T.K. Tsiatsos, Design and evaluation of a simulation for pediatric dentistry in virtual worlds. J Med Internet Res 2013;15(10) [doi: 10.2196/jmir.2651]

[18] M.N. ulos, L. Hetherington, S. Wheeler, Second Life: an overview of the potential of 3-D virtual worlds in medical and health education. Health Info Libr J 2007 Dec;24(4):233-245. [doi: 10.1111/j.14711842.2007.00733.x] [Medline: 18005298]

[19] M. Bell, Toward a definition of vrtual worlds. JVW 2008;1(1):2-5

[20] Warburton S. Second Life in higher education: Assessing the potential for and the barriers to deploying virtual worlds in learning and teaching. British Journal of Educational Technology 2009;40(3):414-426.

[21] Gorman P. Ariadne. 2012. Has Second Life lived up to expectations?URL:http://www.ariadne.ac.uk/issue68/gorm an

[22] Sullivan DK, Goetz JR, Gibson CA, Washburn RA, Smith $\mathrm{BK}$, Lee J, et al. Improving weight maintenance using virtual reality (Second Life). J Nutr Educ Behav 2013 Jun;45(3):264-268. [doi: 10.1016/j.jneb.2012.10.007] [Medline: 23622351]

[23] Culbertson C, Nicolas S, Zaharovits I, London ED, De La Garza R, Brody AL, et al. Methamphetamine craving induced in an online virtual reality environment. Pharmacol Biochem Behav 2010 Oct;96(4):454-460 [FREE Full text] [doi: 10.1016/j.pbb.2010.07.005] [Medline: 20643158]

[24] Kamel Boulos MN, Toth-Cohen S. The University of Plymouth Sexual Health SIM experience in Second Life: evaluation and reflections after 1 year. Health Info Libr J 2009 Dec;26(4):279-288. [doi: 10.1111/j.14711842.2008.00831.x] [Medline: 19930475]

[25] Freeman D, Pugh K, Vorontsova N, Antley A, Slater M. Testing the continuum of delusional beliefs: an experimental study using virtual reality. J Abnorm Psychol 2010 Feb;119(1):83-92 [FREE Full text] [doi: 10.1037/a0017514] [Medline: 20141245]

[26] Gorrindo T, Groves JE. The psychodynamics of transference--a virtual reality model. Am J Psychother 2012;66(2):151-163. [Medline: 22876527]

[27] Yuen EK, Herbert JD, Forman EM, Goetter EM, Comer R, Bradley JC. Treatment of social anxiety disorder using online virtual environments in second life. Behav Ther 2013 Mar;44(1):51-61. [doi: 10.1016/j.beth.2012.06.001] [Medline:23312426]

[28] Lisetti C, Pozzo E, Lucas M, Hernandez F, Silverman W, Kurtines B, et al. Second life, bio-sensors, and exposure therapy for anxiety disorders. Stud Health Technol Inform 2009;144:19-21. [Medline: 19592722

[29] Richardson A, Hazzard M, Challman SD, Morgenstein AM, Brueckner JK. A "Second Life" for gross anatomy: applications for multiuser virtual environments in teaching the anatomical sciences. Anat Sci Educ 2011 Feb;4(1):3943. [doi: 10.1002/ase.195] [Medline: 21265036]

[30] Second Life. Second Life maps URL: http://maps.secondlife.com/secondlife/Imperial\%20Colleg e\%20London/150/86/27

[31] Jane Cook M. Design and initial evaluation of a virtual pediatric primary care clinic in Second Life( $\left({ }^{\circledR}\right)$. J Am Acad Nurse Pract 2012 Sep;24(9):521-527. [doi: 10.1111/j.17457599.2012.00729.x] [Medline: 22931477]

[32] Diener S, Windsor J, Bodily D. Design and development of clinical simulations in Second Life. 2009 Presented at: EDUCAUSE Australasia Conference; May 2009; Perth Australia p. 3-6 URL: https://researchspace.auckland.ac.nz/handle/2292/4305

[33] Schwaab J, Kman N, Nagel R, Bahner D, Martin DR, Khandelwal S, et al. Using second life virtual simulation environment for mock oral emergency medicine examination. Acad Emerg Med 2011 May;18(5):559-562. [doi:10.1111/j.1553-2712.2011.01064.x] [Medline: 21521404]

[34] Creutzfeldt J, Hedman L, Medin C, Heinrichs WL, Felländer-Tsai L. Exploring virtual worlds for scenariobased repeated team training of cardiopulmonary resuscitation in medical students. J Med Internet Res 2010;12(3):e38 [FREE Full text] [doi: 10.2196/jmir.1426] [Medline: 20813717]

[35] Creutzfeldt J, Hedman L, Heinrichs L, Youngblood P, Felländer-Tsai L. Cardiopulmonary resuscitation training in high school using avatars in virtual worlds: an international feasibility study. J Med Internet Res 2013;15(1):e9 [FREE Full text] [doi: 10.2196/jmir.1715] [Medline: 23318253]

[36] Hall V, Conboy-Hill S, Taylor D. Using virtual reality to provide health care information to people with intellectual disabilities: acceptability, usability, and potential utility. J Med Internet Res 2011;13(4):e91 [FREE Full text] [doi: 10.2196/jmir.1917] [Medline: 22082765]

[37] Veronin MA, Daniels L, Demps E. Pharmacy cases in Second Life: an elective course. Adv Med Educ Pract 2012;3:105-112 [FREE Full text] [doi: 10.2147/AMEP.S35358] [Medline: 23762008]

[38] Hussainy SY, Styles K, Duncan G. A virtual practice environment to develop communication skills in pharmacy students. Am J Pharm Educ 2012 Dec 12;76(10):202 [FREE Full text] [doi: 10.5688/ajpe7610202] [Medline: 23275667]

[39] SLurl. Ohio State University Medical Center in Second Life URL: http://slurl.com/secondlife/OSU\%20Medicine/83/98/302

[40] Wiecha J, Heyden R, Sternthal E, Merialdi M. Learning in a virtual world: experience with using second life for medical education. J Med Internet Res 2010;12(1):e1 [FREE Full text] [doi: 10.2196/jmir.1337] [Medline: 20097652]

[41] Patel V, Lee H, Taylor D, Aggarwal R, Kinross J, Darzi A. Virtual worlds are an innovative tool for medical device training in a simulated environment. Stud Health Technol Inform 2012;173:338-343. [Medline: 22357014]

[42] Gordon R, Björklund NK, Smith RJ, Blyden ER. Halting HIV/AIDS with avatars and havatars: a virtual world approach to modelling epidemics. BMC Public Health 2009;9 Suppl 1:S13 [FREE Full text] [doi: 10.1186/14712458-9-S1-S13] [Medline: 19922683]

[43] Cohen D, Sevdalis N, Taylor D, Kerr K, Heys M, Willett K, et al. Emergency preparedness in the 21st century: training and preparation modules in virtual environments. 
Resuscitation $2013 \quad$ Jan;84(1):78-84. [doi: 10.1016/j.resuscitation.2012.05.014] [Medline: 22659598]

[44] Conradi E, Kavia S, Burden D, Rice A, Woodham L, Beaumont $\mathrm{C}$, et al. Virtual patients in a virtual world: Training paramedic students for practice. Med Teach 2009 Aug;31(8):713-720. [Medline: 19811207]

[45] Phillips J, Berge ZL. Second life for dental education. J Dent Educ 2009 Nov;73(11):1260-1264 [FREE Full text] [Medline:19910474]

[46] SLurl. Maryland Dental School in Second Life URL: http://slurl.com/secondlife/UMaryland\%20Dental\%20Scho ol/122/103/45

[47] UMDS Virtual Dental School Insider. 2009. Virtual skull practical URL: http://dspub.umaryland.edu/vi/

[48] Griffith S. Case Western Reserve University. 2008 Jul 28. A virtual toothache helps student dentists learn patient-side communications URL: http://blog.case.edu/casenews/2008/07/28/virtualdentistry

[49] P.E. Antoniou, C. A. Athanasopoulou., E. Dafli \& P.D. Bamidis. Exploring design requirements for repurposing dental virtual patients from the web to second life: a focus group study. Journal of medical Internet research, 16(6) (2014).

[50] Buchanan JA. Experience with virtual reality-based technology in teaching restorative dental procedures. J Dent Educ 2004 Dec;68(12):1258-1265 [FREE Full text] [Medline: 15576814]

[51] Rodrigues M, Silva WB, Barbosa Neto ME, Gillies DF, Ribeiro IM. An interactive simulation system for training and treatment planning in orthodontics. Computers \& Graphics 2007 Oct;31(5):688-697 [FREE Full text] [doi:10.1016/j.cag.2007.04.010]

[52] Marras I, Nikolaidis N, Mikrogeorgis G, Lyroudia K, Pitas I. A virtual system for cavity preparation in endodontics. J Dent Educ 2008 Apr;72(4):494-502 [FREE Full text] [Medline: 18381855]

[53] Papadopoulos L. Virtual reality simulators in dental training. Hel Stom Rev 2010;54(3):263-276.

[54] Hansen MM, Murray PJ, Erdley WS. The potential of 3-D virtual worlds in professional nursing education. Stud Health Technol Inform 2009;146:582-586. [Medline: 19592909]

[55] Wood A, McPhee C. Establishing a virtual learning environment: a nursing experience. J Contin Educ Nurs 2011 Nov;42(11):510-515. [doi: 10.3928/0022012420110715-01] [Medline: 21780735]

[56] Ahern N, Wink DM. Virtual learning environments: second life. Nurse Educ 2010 Dec;35(6):225-227. [doi: 10.1097/NNE.0b013e3181f7e943] [Medline: 20975400]

[57] Warren JJ, Brixey JJ. Second life: not your conventional simulation. Stud Health Technol Inform 2009;146:843. [Medline:19593012]

[58] Schmidt B, Stewart S. Implementing the virtual world of Second Life into community nursing theory and clinical courses. Nurse Educ 2010 Apr;35(2):74-78. [doi: 10.1097/NNE.0b013e3181ced999] [Medline: 20173592]

[59] Trangenstein PA, Weiner EE, Gordon JS, McNew R. An analysis of nursing education's immersion into Second Life, a multi-user virtual environment (MUVE). Stud Health Technol Inform 2010;160(Pt 1):644-647. [Medline: 20841766]

[60] Billingsley L, Rice K, Bennett M, Thibeau S. Using a multiuser virtual environment to facilitate nursing journal clubs: a mixed-methods study. Clin Nurse Spec 2013 Jun;27(3):146-154. [doi: 10.1097/NUR.0b013e31828c8408] [Medline:23575171]
[61] Sweigart L, Hodson-Carlton K. Improving student interview skills: the virtual avatar as client. Nurse Educ 2013 Feb;38(1):11-15. [doi: 10.1097/NNE.0b013e318276df2d] [Medline: 23222623]

[62] McCallum J, Ness V, Price T. Exploring nursing students' decision-making skills whilst in a Second Life clinical simulation laboratory. Nurse Educ Today 2011 Oct;31(7):699-704. [doi: 10.1016/j.nedt.2010.03.010] [Medline: 20807671]

[63] Kidd LI, Knisley SJ, Morgan KI. Effectiveness of a second life(®) simulation as a teaching strategy for undergraduate mental health nursing students. J Psychosoc Nurs Ment Health Serv 2012 Jul;50(7):28-37. [doi: 10.3928/0279369520120605-04] [Medline: 22694785]

[64] Weiner E, McNew R, Trangenstein P, Gordon J. Using the virtual reality world of second life to teach nursing faculty simulation management. Stud Health Technol Inform 2010;160(Pt 1):615-619. [Medline: 20841760]

[65] HealthCyberMap. Social Web ("Web 2.0") and the 3D Web (Virtual Worlds and Second Life) URL: http://healthcybermap.org/sl.htm

[66] E. Mitsopoulou, D. Taibi, D. Giordano, S. Dietze, H. Yu, P. Bamidis, C. Bratsas and L. Woodham Connecting medical educational resources to the linked data cloud: the meducator rdf schema, store and api. Proceedings of the Linked learning 2011: the 1st International Workshop on eLearning Approaches for the Linked Data Age; 2011 May 29-Jun 02; Heraklion, Greece.

[67] P. Bamidis, E. Kaldoudi, C. Pattichis, L. Camarinha-Matos, I. Paraskakis, H. Afsarmanesh, mEducator: A Best Practice Network for Repurposing and Sharing Medical Educational Multi-type Content. Leveraging Knowledge for Innovation in Collaborative Networks. IFIP Advances in Information and Communication Technology 2009;307:769-776. (doi: 10.1007/978-3-642-04568-4_78)

[68] P.D. Bamidis, P. Antoniou, E. Sidiropoulos, Using simulations and experiential learning approaches to train carers of seniors, In 2014 IEEE 27th International Symposium on Computer-Based Medical Systems, DOI 10.1109/CBMS.2014.78.

[69] Meli M. Knowledge Management: a new challenge for science museums. Cultivate Interactive 2003 Feb 07(9):2003

[70] Marcos G, Eskudero H, Lamsfus C, Linaza MT. Data retrieval from a cultural knowledge database. 2005 Presented at: Workshop on Image Analysis for Multimedia Interactive Services; April 13-15, 2005; Montreux, Switzerland.

[71] Mrissa M, Dietze S, Thiran P, Ghedira C, Benslimane D, Maamar Z. Context-based semantic mediation. In: King I, Baeza-Yates R, editors. Weaving Services and People on the World Wide Web. Berlin Heidelberg: Springer; 2009:49-66.

[72] Dunwell I, Petridis P, Protopsaltis A, de Freitas S, Panzoli D, Samuels P. Automating content generation for largescale virtual learning environments using semantic Web services. In: Proceedings of the 5th Workshop on Semantic Wikis (SemWiki-2010). 2010 May 31 Presented at: 5th Workshop on Semantic Wikis (SemWiki-2010); May 31, 2010; Heraklion, Greece.

[73] Edelbring S, Broström O, Henriksson P, Vassiliou D, Spaak $\mathrm{J}$, Dahlgren LO, et al. Integrating virtual patients into courses: follow-up seminars and perceived benefit. Med Educ 2012 Apr;46(4):417-425. [doi: 10.1111/j.13652923.2012.04219.x] [Medline: 22429178] 
[74] Zary N, Johnson G, Fors U. Web-based virtual patients in dentistry: factors influencing the use of cases in the Web-SP system. Eur J Dent Educ 2009 Feb;13(1):2-9. [doi: 10.1111/j.1600-0579.2007.00470.x] [Medline: 19196286]

[75] K. Masters, A Brief Guide to Understanding MOOCs. IJME 1(2) 2009: Available at http://ispub.com/IJME/1/2/10995.

[76] SCORM URL: http://scorm.com/scormexplained/technical-scorm/

[77] J. Kay, P. Reimann, E. Diebold, B. Kummerfeld, MOOCs: so many learners, so much potential. IEEE Intelligent Systems 28(3) (2013):70-77.DOI 10.1109/MIS.2013.66.

[78] N. Sonwalkar, The first adaptive MOOC: a case study on pedagogy framework and scalable cloud architecture-Part I. MOOCs Forum 1(P)( 2013.):22-29 DOI 10.1089/mooc.2013.0007.

[79] D. A. Cook, \& M. M. Triola, Virtual patients: a critical literature review and proposed next steps. Medical education, 43(4) (2009), 303-311.

[80] N. Stathakarou, N. Zary \& A.A. Kononowicz, Beyond xMOOCs in healthcare education: study of the feasibility in integrating virtual patient systems and MOOC platforms. PeerJ, 2 (2014), e672.

[81] N. Stathakarou, N. Zary, A.A. Kononowicz, Virtual patients in massive open online courses-design implications and integration strategies. Studies in Health and Technology Informatics 205. (2014):793-797.

[82] M. Schittek, N Mattheos, H.C. Lyon, R. Attström, Computer assisted learning. A review. Eur J Dent Educ 2001 Aug;5(3):93-100. 